\title{
INTERVIEW WITH PROF. DR. PAULA KALAJA
}

Paula Kalaja, Professor Emerita (University of Jyväskylä, Finland), is one of the pioneers in the use of visual methods in Applied Language Studies, having inspired a range of graduates, post-graduates, and researchers around the world. Her research interests crisscross the use of visual methods, beliefs about languages, language teaching and language learning, and identity, with astonishing creativity and a visionary sense of research. The editors of the special issue "Visual methods in the research with plurilingual audiences: multidisciplinary perspectives" talked to her about how she sees the past, present and future of visual methods in research and teaching, across disciplinary fields, and during and beyond the COVID-19 pandemic.

\section{Paula, what are visual methods and when did you start research with them?}

Visual methods (or methodologies) are in fact tough to define. The term visual can refer to the type data collected for a study, namely, visual data (for example, drawings, photos, collages, video-clips), or possibly combined with other types of data (such as interviews, classroom observations, language learning histories or biographies, and questionnaires). In the latter case, the data would in fact be multimodal, consisting not only of visual data but also of verbal data, or spoken and/or written texts.

Or the term visual can refer to the methods of analysis of pools of data that can be visual and/or verbal. For example, a written language learning history can be analysed for the positive and negative experiences of learning a second language (or an L2) and reported visually as a graph with ups and downs over a longer period of time. These distinctions are comparable to analysis of narratives (one type of data) and narrative analysis (any type of data analysed and findings reported as a narrative).

After graduating (with a $\mathrm{PhD}$ degree from Georgetown University, Washington, DC) and returning home I have been working for the Department of Languages (these days: the Department of Language and Communication Studies) at the University of Jyväskylä, Finland. On our campus, teacher education is a joint effort of four units: our department, the Department of Teacher Education, the Teacher Training School (Grades 1-12), and the Language Centre (these days: the Centre for Academic Multilingual Communication).

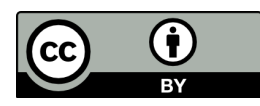


When giving courses to our student teachers (or pre-service teachers) one of my major concerns has always been what sense our studies make to them (mostly English majors and minors), considering that the field of Applied Language Studies (or L2 learning and teaching, or L2 education) are full of controversies and conflicting research findings. Graduating from our MA programme and becoming an L2 teacher is in fact a life-long process, and it involves identity work on the part of our students: from learners of English as a foreign language to professionals in the field of teaching English as a lingua franca.

In local cooperation, we (Sirpa Leppänen, Hannele Dufva and me) started collecting language learning histories or written narratives from our students (and also from practicing L2 teachers by organising a writing competition) for two reasons: firstly, to give our students an opportunity to reflect on their own careers as learners of English (this has been done as part of their course work in the English Section of our department); and secondly, to do research. (see, for example, Kalaja, 2015).

It was only later that we started exploring the possibilities of drawings or visual narratives to recollect past experiences of learning L2s, and/or trying out different tasks to envision future events of teaching L2s. Since then we (Hannele Dufva, Riikka Alanen and me) have collected both types of data from our students and followed one group over a period of five years in a major research project, and so we also have longitudinal data (Kalaja, Alanen, \& Dufva, 2008; Kalaja, 2019). These pools of data, or sets of verbal and/or visual narratives, have made it possible to trace the developments in our students' identities, beliefs, agency and visions (a construct related to motivation and willingness to invest) in the course of their studies with us. Most recently, we (Katja Mäntylä and me) have been co-teaching an introductory course to our students. We have continued exploring the possibilities of visual data in looking forward in time by asking these students only half-way in their studies to envision their future as professionals within our educational system visually and partly verbally (Kalaja \& Mäntylä, 2018; Mäntylä \& Kalaja, 2019).

In addition to local cooperation, I became gradually aware of the work of researchers in different parts of the world, all making use of visual data and/or analysis. In the meantime, I had also revised my understanding of a related key term, namely, multilingualism, questioning the assumptions related to native-speakerism or the monolingual bias. I am now an advocate of dynamic or holistic multilingualism and realise that most people are in fact multilingual, and thus everyone has more than one language (or more than one 
variety of a single language) in their repertoire that they can draw on, depending on the situation. In other words, they do translanguaging. And so everyone possesses a unique multicompetence that will evolve over time and that they should be proud of (instead of feeling inferior or defective in comparison to the idealised "assumedly fully competent" L1/native speakers).

The intensive international cooperation has resulted in two major publications in the past few years: a double special issue of Applied Linguistics Review (2018), edited by me and Anne Pitkänen-Huhta; and Visualising multilingual lives (2019), a collection of articles, edited by me and Sílvia Melo-Pfeifer. (As an aside: the latter was one of the four candidates for BAAL Book Prize 2020, which we are thrilled about!) These publications contain reports on various aspects of becoming or being multilingual as lived accessed by visual (or multimodal) means.

\section{What do you think visual methods bring to research that other methods do not? Can you give some examples?}

The (fine) arts can be divided into different types: literary, performance, auditory and visual arts. The visual arts or their products appeal to the visual sense but can engage other senses, too. The visual arts include, among others, drawing, photography, painting, film and sculpting, and they are mainly created for aesthetic purposes and judged for beauty. However, they can also be used to tackle complex or sensitive issues and to express opinions or emotions.

Thus visual methods have been used in disciplines, such as anthropology, sociology and psychology, and now also in Applied Language Studies, but these have been used for instrumental purposes (instead of aesthetic purposes) initially to describe multilingual environments (see Question 4 later) and more recently to address aspects of becoming or being multilingual.

The use of visual methods has been our response to the recent call to broaden the methodologies in our field (see Question 6 later). There are a number of reasons for this. Firstly, visual methods can give participants in studies, be they learners, teachers, and users of more than one language, an alternative way of expressing themselves, in contrast to verbal means, whether written or spoken. This might be the case especially with issues that are complex, controversial, or sensitive in nature. Some might prefer 
tackling issues like this visually instead of verbally. (But the reverse can also be true.) Secondly, people are now used to the increasing use of visual means of communication in their everyday lives: consider, for example, Instagram, Snapchat, YouTube, TikTok, and Facebook. Thirdly, Finland has become more and more multilingual and multicultural because of an increasing number of immigrants to the country in the past few years. So, communication or sharing experiences verbally can be a challenge in pursuing research. In addition, there are power issues involved, if Finnish were insisted to be used in interviews with participants with a limited knowledge of the language. Furthermore, it would be impossible to ask small children or illiterate adults (which is often the case with immigrants to the country), for example, to write a language learning history or fill in a questionnaire in Finnish or in any language. Finally, some occasions of learning, teaching and/or using more than one language may have been negative or even traumatic experiences, possibly requiring psychological treatment or therapy, and so it might be easier to handle/share experiences like this by visualising than by putting into words. I am reminded of/haunted by Dangerous multilingualism (2012), a collection of articles edited and/or written by Jan Blommaert and some of my colleagues (Blommaert et al., 2012). They describe the current situation in Finland: "Not all forms of multilingualism are productive, empowering and nice to contemplate. Some - many - are still unwanted, disqualified or actively endangering to people." (Blommaert et al., 2012, p. 1).

\section{What are the main themes of your research with visual methods? Can you please propose some research themes to our readers, in case they would like to implement them as well?}

As I mentioned earlier, my teaching (and being an L2 teacher educator) and research have gone hand in hand. So, in most of my/our studies I/we have had our students as participants. I do realise that our students are a privileged group: they have studied at least two L2s in the course of their school careers (Grades 3-12): as a rule English from Grade 3, followed by Swedish (as a compulsory subject), and possibly other languages spoken in Europe, such as German, French, Russian and Spanish, in different stages of their studies. Our students have been among the best in their studies in English, judged by the results of the Matriculation Examination, taken before they graduated from Grade 12. In a way, they represent elite multilingualism, having enjoyed regular teaching and assessment of their progress, and taught by qualified teachers of L2s and in classrooms equipped with modern IT and sets of textbooks. In other words, this kind of multilingualism is 
multilingualism by choice - in contrast to multilingualism by force or of necessity and without hardly any threat to their L1.

However, our students will be faced with new challenges once they enter working life as qualified teachers of English (or other L2s), as we (Riikka Alanen, Hannele Dufva and me) have been pointing out (Kalaja, Alanen, \& Dufva (2018). Finland, with a population of 5.5 million, and so also students in schools are much more multilingual and multicultural than ever. Until recently it was easy to switch occasionally to Finnish in teaching English or use textbooks with grammar explanations in Finnish and bilingual vocabulary lists: English-Finnish or Swedish, the second national language. But this will not do in some classes anymore, especially in major cities, as the majority of students might have some other language than Finnish or Swedish as their L1! So, this calls for quite different practices in teaching English (and other L2s) in the country. One solution would be to resort to translanguaging pedagogy or giving multilingual classes where different languages are taught/used at the same time, compared and contrasted now that the study of the first L2 begins from Grade 1 (or even earlier) since the revision of the national core curriculums for Grades 1-12, effective from August 2016. So far, we have seen only some small-scale experimentation along these lines.

Another challenge is that students are these days exposed to English and use the L2 in their everyday lives and pick it up that way instead of studying textbooks, whether printed or e-versions, or formal teaching. Yet another challenge is that with the changing status of English from a foreign language into a lingua franca has resulted in a decrease in students' motivation to study any other L2s: knowing English is enough, they and possibly their parents seem to think. And this worries not only teachers of other L2s (with fewer job opportunities) but also the Government (with the diminishing and narrowing of the national language reserve or overall knowledge of different languages by Finns).

At any rate, a further distinction needs to be made regarding the term multilingualism: multilingualism as objectively described and as subjectively experienced or as lived. It is one thing to study an L2, make progress in it, measured, for example, by taking the Matriculation Examination or using the CEFR proficiency rating scale. It is quite another thing how you have experienced your efforts to learn the L2, involving ups and downs, positive and negative events, joy and frustration, and success and failure. This is not only true of L2 learners but also of L2 teachers in pursuing their careers, and users of more 
than one language in their everyday lives. The latter line of research, or multilingualism as lived, seeks to find out what sense languages make - cognitively and emotionally - to multilinguals, and research has addressed issues such as their past experiences, beliefs about different languages or their learning, teaching or use, identities, literacies, and visions of their future. And the two publications that I mentioned earlier in answering Question 1, with a total of 24 reports, illustrate the range of issues addressed in research so far. Besides, they illustrate not only multilingualism by choice that I discussed earlier but also by force or of necessity, and the reports on the latter type of multilingualism, especially, are at times emotionally trying reading to those only/mostly with experiences of the former type of multilingualism. When editing some of the manuscripts for the first publication, I ended up with tears in my eyes. Later I heard that so had my co-editor, Anne Pitkänen-Huhta!

\section{Can you imagine or do you know of other research fields using visual methods? Do they study the same phenomena?}

Applied Language Studies has undergone a number of turns in the past few years: firstly, the narrative turn; secondly, the affective turn; thirdly, the multilingual turn; and fourthly (and most recently), the visual turn. So visualising is a fairly recent phenomenon in our field, and it started with studies that focused on the environments, especially in major cities in different parts of the world where people are exposed to a number of different languages in their everyday lives (public street signs, advertising billboards, shop signs, etc.) or in their jobs, including schools. So, these studies have been about linguistic landscapes, ranging from London and Barcelona to Singapore and Tokyo, or schoolscapes, and these have for the most part been documented by taking photos.

In contrast, the recent studies by us and our international colleagues (reported, among others, in the two publications that I mentioned earlier in answering Question 1) have focused on multilingualism as experienced or as lived by learners, teachers or users of more than one language: how do they cognitively and emotionally relate to the languages in their repertoires, and what consequences does this have, for example, on their identities, beliefs about L2 learning and teaching, visions, and literacies in the specific contexts where they find themselves? In the studies along these lines, the methods have been much more varied, including different types of visual data, both two- and three-dimensional, possibly complemented with verbal data. 
These lines of research mark a new methodological turn in Applied Language Studies, making use of visual data and/or methods of analysis.

Personally, I had initially been intrigued by research in some other disciplines. For example, Karin Aronson and Sven Andersson (1996) had asked children to produce drawings of classroom life, and they analysed these for the relationship of those involved, namely, learners and their teacher, and found cultural differences. And I had heard in passing about Hans-Jürgen Krumm and his work on self-portraits of multilinguals (without access to his reports for years), and then I ran into an article by Brigitta Busch (2006). She had adopted his methodology and asked multilingual people in her specific context to indicate what role the languages that they knew played in their lives by mapping these on a standardised drawing of a human body and by using colours for highlighting. Or to put it another way, the participants had been provided with a template to complete. Since then research along these lines has been flourishing!

But it took me/us some time to pluck up the courage to begin to explore the possibilities of visual methods in our own context.

\section{Regarding now the analysis of visual material: is there any method of particular importance? How can you be sure of the accuracy of the analysis and interpretation of the data? Do visuals really "talk"?}

I recommend anybody interested in the analysis of visual material or images to consult a comprehensive review by Gillian Rose (2016). In principle, the focus (or as she puts it: site) of analysis (or what one wishes to do research on) can be one of the following: the production of the image, the image itself, circulation, or audiencing. Depending on the focus or site (not all are necessarily relevant for those doing research in Applied Language Studies), the researcher can resort to a total of eight ways of analysing visual data or multimodal data, if visual data are complemented with other types of data: compositional interpretation, content analysis, semiotics, psychoanalysis, discourse analysis, critical discourse analysis, ethnography, and finally, digital methods.

Of these, the two most frequently used in Applied Language Studies seem to be: compositional analysis and content analysis, or a combination of the two. Compositional analysis focuses on the formal aspects of images (for example, by paying attention to the size or placements of specific items or the use of colours in portraits of L2 learners 
or teachers. Content analysis, in contrast, focuses on what the images depict or portray and how these might relate to the discourses in the context of the study or in society at large. For some sample studies in our field you can consult the two publications that I mentioned earlier in answering Question 1.

In my opinion, no type of data speaks for itself! You always view your data through a specific pair of lenses (or framework), and so analysis involves interpretation no matter what type of data you have at hand: oral, written, visual, multimodal, or even numerical. So, you need to be open about the stages and decisions made in the processing (or coding) and interpreting your pool(s) of data, provide readers/listeners with examples and be explicit about your conclusions. It needs to be born in mind that there is always an element of subjectivity involved. Besides, a researcher might end up with quite different interpretations of the same pool of data viewed through another pair of lenses (or framework). Consider, for example, the lessons from a report by Kristiina Skinnari (2019).

Or the interpretations (or findings) of two different types of pools of data from the same group of participants can be similar - or dissimilar. In a case study of two of our students as part of our project that I mentioned earlier, we (Riikka Alanen, Hannele Dufva and me) had asked them to write life stories about their experiences of learning English and to draw self-portraits of themselves as learners of the L2, complemented with verbal commentaries (Kalaja, Alanen, \& Dufva, 2011, Kalaja, 2019). In the case of Ann, the two pools of data told the same story but not in the case of Eve! Ann emphasised the social/ interactive nature of her learning of the L2 and her identity as a user of the L2 in both pools of data. In contrast, in her self-portrait Eve emphasized the individual/cognitive nature, but in her life story the social/interactive nature of her learning of the L2 and her identity as a learner of the L2, even though she had attended an English-medium school in Grades 10-12. So, a lesson from this case study is that the triangulation of pools of data might increase the reliability of your study (but not necessarily).

Furthermore, a related issue is that participants can always interpret the instructions or the tasks that they have been asked to carry out (just like interview questions or questionnaire items or their response alternatives) differently from what was intended by researchers, resulting in greater variation in the data collected than you might have wished for. For example, in our research project mentioned earlier in my response to Question 1, when we asked our students to draw self-portraits of themselves as learners of an L2, some of them 
resorted to a metaphor. As interesting/creative as the visual metaphors were (including water being poured into a glass that was only half-full, a rug that was unfinished with a few patches still missing, or a plant in need of sunshine, water and fertile soil in order to blossom), we decided to ignore them partly for their small number. But one could consider making use of visual metaphors as the main type of data ...

\section{Do you remember any criticism regarding the use of visual methods when you submit your work to peer-review? Can you share them with our readers? How did you manage to convince the editors or the peer-reviewers of the well-founded nature of these methods?}

Earlier on in answering Question 4 I talked about the different turns that Applied Language Studies have undergone in the past few years and mentioned the visual turn. In research on multilingualism, linguistic data, or oral and written texts, have dominated the field, and so data have been collected by interviewing multilinguals (be they learners, teachers or users of more than one language), by asking them to fill in questionnaires, or by producing narratives (or language learning or teaching histories, life stories or autobiographies) either in writing and/or orally. In addition, classrooms have been observed by audio- or video recording classroom interaction. In other words, verbalising, or as some have put it, lingualism, has ruled research in the field.

It is only recently that visualising has begun to be explored as an alternative/legitimate means of making sense of issues related to aspects of becoming or being multilingual. The analysis of visual data is of course a new challenge for researchers in our field, as we have as a rule been trained only/mainly to work with linguistic data.

Initially within the major project mentioned earlier under Question 1, we (Riikka, Hannele and me) asked, among others, our students to produce their self-portraits as learners of an L2 and to provide their own interpretations in a couple of sentences on the reverse side of the task sheet. But the interpretations turned out to be quite varied, so comparing them was a challenge for us. On the other hand, they did help somewhat in the coding of the visual pool of data, when in doubt. Later, when we (Katja and me) asked another group of our students to envision their future as L2 professionals visually, we provided them with a set of questions to elaborate on the various aspects of their visions to ensure greater comparability in the pools of data. So, in fact our pools of data have been multimodal. These have been our ways to play it safe and avoid crude misinterpretations in analysing 
the pools of data collected from our students Alternatively, we could have interviewed the students (but they were too many in number), as some other researchers/ colleagues have done ...

I am reminded of a study by two of my colleagues, Anne Pitkänen-Huhta and Tarja Nikula (2013). On occasions, Anne has shared the following incident with us - with a lesson. Anne and Tarja had been working on a research project where they wanted to find out what English as an L2 meant to teenagers in Finland (Grade 8 or 9 students, N =8), compared to Finnish, their L1. The students had been asked to take photos about their use(s) of the two languages and compile collages with titles "English and me" and "Finnish and me". One of the participants, a young man, had taken, among others, a photo of a skateboard. My colleagues had initially coded it as 'using English in pursuing a spare time activity': skateboarding. When my colleagues interviewed the student, it turned out that the photo was indeed about using English, but it had been used for quite a different purpose: to express negative feelings or to swear, as the young man was so upset about his skateboard. He found it easier to vent his feelings in English than in the L1. The photo had depicted a skateboard but a broken one!

Another way of avoiding misinterpretations (or increasing the reliability of your findings) would be to give the participants in a study a more active role. They could act as coresearchers in the analysis and coding of the pools of data collected and/or be asked for their interpretations and/or explanations/justifications. Or you could check afterwards whether your own interpretations sounded correct - in their opinion. Both are procedures to be highly recommended, if only logistically possible!

Overall, regarding reporting in speaking and/or in writing about our studies that have made use of visual (or multimodal) data and/or analysis, there are always those in the listeners and/or readers who have been fascinated by our findings but also those who have their reservations and doubts! But the publishing of Visualising multilingual lives (see Question 1) in 2019 marks, in my opinion, that this type of research is beginning to be recognised as an equally legitimate methodology in pursuing research on multilingualism as lived! And all visual data were published in their original colours (instead of blackand-white). I had negotiations with representatives of quite a number of publishers: Multilingual Matters was the only one that did some financial calculations and agreed to do so (e-journals are a different matter)! Also consider the recognition the publication 
received from key people in Applied Language Studies in September 2020 (explained under Question 1)! So, I am being positive/optimistic ...

7. How do you see the future of visual methods in research? And beyond research, what role could they play in the daily life of teaching and learning, at the university and in other learning contexts?

Question 1: In research

I addressed this issue briefly in answering Question 6.

Question 2: Beyond research

Until recently there was a shared understanding of the aims in teaching L2s in Europe, compiled into The Common European Framework of Reference for Languages or CEFR (2001): every citizen in any European country should aim to learn another two languages in addition to their L1, all assumed to be European languages, and English being as a rule one of these (see my elaborations on this point earlier in answering Question 3). This in fact seems to have fostered elite multilingualism on the continent. However, the recent increased migration to Europe, and even within Europe, for a number of reasons has resulted in immigrants in European countries to be much more varied in their linguistic backgrounds, or to put it in another way, they have much richer repertoires of $\mathrm{L} 1 \mathrm{~s}$, heritage and minority languages than ever imagined! This has resulted in the revising of the CEFR and its original aims and acknowledging multilingualism of the other type, namely, multilingualism by force, too.

In Finland this resulted in revising the national core curriculums for Grades 1-12. So, now the first aim in L2 teaching and learning (or L2 education) is to increase learners' awareness of languages, and of multilingualism and multiculturalism. The second aim is to provide learners with practice in learning-to-learn skills, including learning strategies. The third aim is to develop learners' proficiency or competence in the L2s. Overall, the revisions meant that the order of the three main aims was reversed, and thus, the current Finnish core curriculums seem to highlight the importance of fostering language and intercultural/culture awareness, despite some differences in the terminology used in the different official documents. 
Earlier on I said that my/our teaching and research have gone hand in hand. This is also true of the application of visual methods: these have been used for research purposes but importantly also to raise our students ' awareness of aspects of becoming and being multilingual in an attempt to tackle issues such as the monolingual bias or nativespeakerism. Recently, Anne and I (2020) realised (inspired by a call for papers for another special issue) that the 24 studies reported in the two publications mentioned earlier in answering Question 1 had even greater potential: they could be adapted to raise the language and culture awareness (or of multilingualism and multiculturalism) of any student within our educational system (and even elsewhere), ranging from small children to adults or retired people, attending evening classes of L2s. So, we ended up adapting a set of tasks and chose students in Grades 7-9 to be the target group: by that time, the students would already have experience of studying English and least another L2s. In designing the tasks, our idea was to provide the students with an opportunity to reflect on their own learning of L2s (or additional languages) over their school careers. All the tasks make use of visual methods of one type or another. Overall, the tasks focus on the learning of L2s as subjectively experienced by the students: in their roles as learners of L2s over their school careers so far and as envisioned in the years to come, and/or as users of more than one language. While interacting with others in specific places or spaces, including home and school, the languages can take on different roles and/or significance. These are all important issues to address in raising awareness of multilingualism and multiculturalism (or language and culture awareness) and to keep up students ' motivation in any stage of their studies and to reach the goal of learning L2s as a life-long venture. And in our opinion, the set of tasks could easily be adapted for other groups of L2 learners, younger or older (Kalaja \& Pitkänen-Huhta, 2020).

On a more critical note, I recently ran into an article by Shelley Taylor and her colleagues (Taylor, Despagne \& Faez, 2018). They seem to be advocating for even more critical language awareness (CLA), which could be worth pursuing, considering the current situation, for example, in Europe (but also elsewhere), and suggest topics that could be addressed with L2 learners and stages that could be taken in enhancing their CLA (and that of their teachers in teacher education). But the paper suggests only verbal means (not visual ones) that one could use for these purposes!

\section{We are doing this interview with you remotely, in a time disgracefully marked by the COVID-19 pandemic. How do you see the collection of visual materials during}




\section{the pandemic, in on-line teaching and learning? And, in another vein, how could we use visual methods to document and study the pandemic?}

\section{Question 1:}

Schools (including colleges and universities) in different parts of the world were surprisingly fast able to shift to distance- or online teaching and learning (with all fancy applications) once it became too risky for students to attend regular classes because of the COVID-19 pandemic.

Modern IT offers plenty of possibilities to make use of visual material, such as computergenerated images, photographs, blogs and vlogs. Some of these can be characterised as still images, others moving images, possibly combined with text and/or sound (in which case the material would in fact be multimodal). In my opinion, their possibilities have not yet been exhausted!

So far most of the material has been two-dimensional; and so little use has been made of three-dimensional data, such as dioramas: for inspiration, you can consult a study by Katja Frimberger and her colleagues (Frimberger, White \& Ma, 2018). They asked young refugees under 21 years of age in the UK to produce identity boxes of themselves as multilinguals (with up to three or four languages already in their repertoires). The boxes (comparable to shoe boxes) consisted of small figures of human beings or animals, photos, slogans, etc. Interestingly, the researchers were so impressed by the identity boxes and the informal talks that they had had with the refugees in their rudimentary English, while they were compiling them, and so they ended up writing commentaries (or as they put it, vignettes) and using very simple English - in return - to make sure the participants were able to understand their texts! If sharing face-to-face should not be possible, you could take photos of the dioramas and share them on-line, or by skyping, right?

A related issue regards the production of the visual material for any study: who produces it? The participants on their own, or in cooperation with their co-participants and/or teachers, or by the researcher, possibly based on other type(s) of data collected from the participants? Again, for inspiration you can consult the two publications that I mentioned earlier in answering Question 1. 


\section{Question 2:}

The COVID-19 pandemic is indeed a global phenomenon: over 30 million people have already caught the virus and a million lost their lives (by September 18, 2020), so it has affected everybody one way or another. And there is plenty of disinformation and misinformation (or consciously or unconsciously misleading information) around the pandemic in the different media. The recommendations by public health authorities or by representatives of the Government (and even by some Presidents) have been changing over time and/or have been controversial to start with. Consider, for example, the use of masks: to use or not to use them? And our understanding of the virus, its workings and symptoms, compared to other diseases, have been evolving over the past few months. So, what do ordinary people (of different ages: from small children to elderly people at risk) and with different language backgrounds and skills in the L1 or L2s make of all this? And based on which sources of information, and in which languages?

The pandemic reminds me of a study by Ava Becker-Zayas and her colleagues (BeckerZayas, Kendrick \& Namazzi, 2018), published in the double-special issue of a journal that I mentioned earlier in answering Question 1. The researchers worked in Uganda and were concerned with the literacy skills of children regarding another acute/sensitive health issue, namely, AIDS/HIV. A group of multilingual children were asked to produce billboards with their own interpretations of the disease in English, the medium of instruction in their school, after having studied official billboards issued by local health authorities. I can envision this study to be adapted in tackling the controversies around the COVID-19 virus ... with participants of any age and in any language! Go for it!

Thank you ... and wishing everybody: Happy European Day of Languages (celebrated on September 26)!

Interviewed by

Sílvia MELO-PFEIFER (Universität Hamburg) Bruna Pupatto RUANO (UFPR) Francisco CALVO DEL OLMO (UFPR) Tatyana FRIEDRICH (UFPR) 


\section{REFERÊNCIAS}

ARONSSON, K.; ANDERSSON, S. Social scaling in children's drawings of classroom life: A cultural comparative analysis of social scaling in Africa and Sweden. British Journal of Developmental Psychology, v. 14, p. 301-314, 1996.

BECKER-ZAYAS, A.; KENDRICK, M.; NAMAZZI, E. Children's images of HIV/ AIDS in Uganda: What visual methodologies can tell us about their knowledge and life circumstances? Applied Linguistics Review, v. 9, n. 2-3, p. 365-389, 2018.

BUSCH, B. Language biographies: Approaches to multilingualism in education and linguistic research. In: BUSCH, B.; JARDINE, A.; TJOUTUKU, A. (Ed.), Language biographies for multilingual learning. Cape Town: PRAESA, 2006. p. 8-18.

COUNCIL OF EUROPE. Common European framework of reference for languages: Learning, teaching, assessment. Cambridge: Cambridge University Press, 2001. Retrieved from: https://rm.coe.int/CoERMPublicCommonSearchServices/ DisplayDCTMContent?documentId=0900001680459f97

FRIMBERGER, K.; WHITE, R.; MA, L. "If I didn't know you what would you want me to see?": Poetic mappings in neo-materialist research with young asylum seekers and refugees. Applied Linguistics Review, v. 9, n. 2-3, 2018. p. 391-419.

BLOMMAERT, J.; LEPPÄNEN, S.; PAHTA, P.; RÄISÄNEN, T. (Ed.). Dangerous multilingualism: Northern perspectives on order, purity and normality. Basingstoke: Palgrave Macmillan, 2012.

KALAJA, P. A review of five studies on learner beliefs about second language learning and teaching: Exploring the possibilities of narratives. In: JAKONEN, T.; JALKANEN, J.; PAAKKINEN, T.; SUNI, M. (Ed.), Kielen oppimisen virtauksia. Flows of language learning. Jyväskylä: AFinLA, 2015. p. 21-38. Retrieved from: http://ojs.tsv.fi/index.php/ afinlavk/article/view/53193

KALAJA, P. Doing research on learner beliefs about L2 learning and teaching: Exploring the possibilities of visual narratives. In: BARAJAS, E. R. E. (Ed.), Research on beliefs about foreign language learning and teaching. Mexico City: Editorial Fontamara, 2019. p. 37-67.

KALAJA, P.; MELO-PFEIFER, S. (Ed.). Visualising multilingual lives: More than words. Bristol: Multilingual Matters, 2019. 
KALAJA, P.; MÄNTYLÄ, K. "The English class of my dreams": Envisioning teaching a foreign language. In: MERCER, S.; KOSTOULAS, A. (Ed.), Language teacher psychology. Bristol: Multilingual Matters, 2018. p. 34-52.

KALAJA, P.; PITKÄNEN-HUHTA, A. (Ed.). Visual methods in Applied Language Studies. Applied Linguistics Review, v. 9, n. 2-3 (Double special issue), 2018.

KALAJA, P.; PITKÄNEN-HUHTA, A. Raising awareness of multilingualism as lived - in the context of teaching English as a foreign language. Language and Intercultural Communication, v. 20, n. 4, p. 340-355, 2020. Retrieved from: https://www.tandfonline. com/doi/full/10.1080/14708477.2020.1786918

KALAJA, P.; ALANEN, R.; DUFVA, H. Self-portraits of learners of EFL: Finnish students draw and tell. In: KALAJA, P.; MENEZES, V.; BARCELOS, A. M. F. (Ed.), Narratives of learning and teaching EFL. Basingstoke: Palgrave Macmillan, 2008. p. 186-198.

KALAJA, P., ALANEN, R.; DUFVA, H. Teacher trainees' beliefs about EFL learning in the light of narratives. In: BREIDBACH, S; ELSNER, D.; YOUNG, A. (Ed.), Language awareness in teacher education: Cultural-political and social-educational perspectives. Frankfurt am Main: Peter Lang, 2011. p. 63-78.

KALAJA, P.; ALANEN, R.; DUFVA, H. ELT in Finland. In: Liontas, J. I.; DelliCarpini, M. (Ed.), The TESOL encyclopaedia of English language teaching. Hoboken, NJ: Wiley-Blackwell, 2018. Retrieved from: https://onlinelibrary.wiley.com/doi/ pdf/10.1002/9781118784235.eelt0930

MÄNTYLÄ, K.; KALAJA, P. “The class of my dreams” as envisioned by student teachers of English: What is there to teach of the language? In: KALAJA, P.; MELO-PFEIFER, S. (Ed.), Visualising multilingual lives: More than words. Bristol: Multilingual Matters, 2019. p. 254-274.

PITKÄNEN-HUHTA, A.; NIKULA, T. Teenagers making sense of their foreign language practices: Individual accounts indexing social discourses. In: BENSON, P.; COOKER, P. L. (Ed.), The applied linguistic individual. Sociocultural approaches to identity, agency and autonomy. Sheffield: Equinox, 2013. p. 104-118.

ROSE, G. Visual methodologies: An introduction to researching with visual materials (4th revised ed.). Los Angeles, CA: Sage, 2016.

SKINNARI, K. Looking but not seeing: The hazards of a teacher-researcher interpreting self-portraits of adolescent English learners. In: KALAJA, P.; MELO-PFEIFER, S. (Ed.), Visualising multilingual lives: More than words. Bristol: Multilingual Matters, 2019.p. 97-114. 
TAYLOR, S. K.; DESPAGNE, C.; FAEZ, F. Critical language awareness. In: Liontas, J. I. (Ed.), The TESOL encyclopaedia of English language teaching. Hoboken, NJ: John Wiley \& Sons, 2018. Retrieved from: https://onlinelibrary.wiley.com/doi/ abs/10.1002/9781118784235.eelt0660 